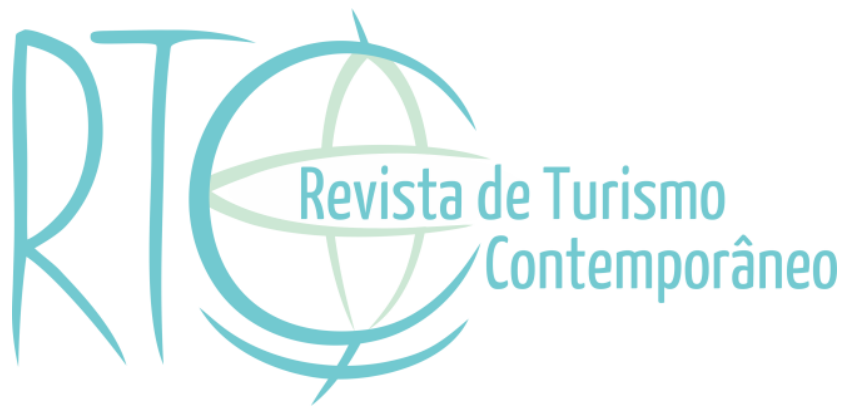

\title{
Pesquisa empírica: turismo em áreas naturais e o uso do marketing sustentável ${ }^{1}$
}

\section{Empirical research: tourism in natural areas and the use of sustainable marketing}

\section{Camila Belli Kraus}

Professora orientadora de pós-graduação do Centro Universitário Leonardo da Vinci UNIASSELVI, Indaial/SC, Brasil

E-mail: kmilabk@gmail.com

Rosiane Mesquita Gomes Ricci

Professora do Instituto Federal do Maranhão - IFMA, São Luís/MA, Brasil

E-mail: rosemgricci@ifma.edu.br

\section{Glaubia Santos}

Mestranda em Turismo e Hotelaria pela Universidade do Vale do Itajaí - UNIVALI, Itajaí/SC, Brasil

E-mail: glaubiass@gmail.com

Paulo dos Santos

Professor e pesquisador da Universidade do Vale do Itajaí - UNIVALI, Itajaí/SC, Brasil E-mail: pires@univali.br (CAPES) - Código de Financiamento 001. 


\section{RESUMO}

O presente artigo apresenta o estado da arte relativa ao marketing sustentável, bem como o turismo em áreas naturais. Baseado neste contexto, o trabalho tem como objetivo refletir sobre a importância do marketing sustentável como ferramenta que possa fortalecer a competitividade da atividade turística em áreas naturais. Foi realizado por meio de revisão bibliográfica sobre o marketing e turismo sustentável. Nesse contexto, foi possível identificar a correlação entre os temas abordados, pois os princípios da sustentabilidade prezam pela conservação dos fatores culturais, sociais e ambientais e o marketing sustentável surge como um potencial de integração de ações voltadas para a disseminação dos valores ambientais.

Palavras-chaves: Marketing Sustentável. Turismo. Sustentabilidade. Marketing. Áreas Naturais.

\section{ABSTRACT}

This paper presents the state of the art relating to sustainable marketing and tourism in natural areas. Based on this context, the work aims to reflect on the importance of sustainable marketing as a tool that can strengthen the competitiveness of tourism in natural areas. It was carried out through bibliographic review on marketing and sustainable tourism. In this context, it was possible to identify the correlation between the themes addressed, since the principles of sustainability emphasize the conservation of cultural, social and environmental factors and sustainable marketing emerges as a potential for integration of actions aimed at the dissemination of environmental values.

Keywords: Sustainable Marketing. Tourism. Sustainability. Marketing. Natural Areas. 


\section{INTRODUÇÃO}

A discussão ganha força a respeito do marketing sustentável como uma nova ferramenta que possa atingir adeptos da sustentabilidade e também procuram unir lazer com qualidade de vida. O turismo em áreas naturais protegidas é opção de destino de muitas pessoas, o qual necessita inserir um bom plano de manejo, boa infraestrutura, bem como a preocupação com a sua preservação (Meneguel \& Etchebehere, 2011).

Por meio deste ensaio teórico pretende-se apresentar pontos relevantes e questionamentos pertinentes ao Marketing sustentável como ferramenta que possa potencializar a competitividade de destinos turísticos, e valorizando neste contexto sua sustentabilidade. Tem por base o questionamento de como o marketing pode influenciar na competitividade e sustentabilidade de destinos turísticos naturais.

Este artigo busca mostrar a relação entre turismo sustentável em áreas naturais protegidas da categoria "parque" com o marketing sustentável e como este pode contribuir para o desenvolvimento da atividade turística de determinada região. O turismo sustentável está atrelado à integração aos seguintes aspectos: a integridade ambiental, desenvolvimento econômico e sociocultural. Essa tríplice da sustentabilidade tem como principio garantir a conservação dos recursos naturais e culturais (Leroux, 2010; Falcão \& Gómes, 2012; Niedziólka, 2014) e vão de encontro com as características do marketing sustentável utilizadas para atrair os turistas que buscam qualidade de vida e que estão preocupados com o reflexo de suas ações relacionados ao impacto que pode causar no meio ambiente e saúde, buscando cada vez mais, informações sobre consumo consciente, assim como, destinos que lhes ofereçam as características compatíveis com seus valores sustentáveis (Silva, Minciotti \& Romeiro, 2011).

Com este artigo pretende-se fazer uma reflexão teórica em torno do papel do marketing de destinos enquanto ferramenta de desenvolvimento do turismo sustentável em áreas naturais protegidas com objetivo de refletir a importância do marketing sustentável para fortalecer a competitividade da atividade turística.

Os objetivos do turismo sustentável estão vinculados a uma estratégia que visa um crescimento do número de visitantes comprometidos com os princípios sustentáveis. No entanto para alcançar esse objetivo é preciso seguir aspectos específicos (Niedziólka, 2014). A partir desse contexto, este estudo apresenta as variáveis verificadas pela pesquisa que orientam a discussão dos resultados: 
a) Organização de todos os atores interessados em desenvolver o turismo de determinada comunidade; detectar os produtos turísticos;

b) Prezar por unir o interesse da localidade, do meio ambiente no desenvolvimento das atividades e do produto e marketing sustentável;

c) Verificação desse marketing em relação à visão de possíveis compradores; atribuir estratégias voltadas para atividades de visão, missão e plano de marketing em longo prazo;

d) Criar marca comum da região (Niedziólka, 2014).

Para tanto, realizou-se um levantamento bibliográfico em torno das temáticas de marketing sustentável e turismo sustentável, se apropriando dos conceitos dos autores para direcionar a discussão fomentando a importância desta para academia assim como para sociedade envolvida com as questões ambientais.

\section{MARKETING SUSTENTÁVEL}

O marketing tem como principal função estabelecer uma conexão entre produto e mercado. A busca pela satisfação é essencial para que qualquer produto obtenha êxito num determinado mercado. Desta forma num cenário competitivo em que as organizações estão imersas é essencial aprofundar conhecimentos na formação de estratégias, na construção de um marketing competitivo e eficiente (Toaldo \& Luce, 2006).

O objetivo principal do marketing no mundo cada vez mais consumista é satisfazer e atender as necessidades dos consumidores visando estabelecer uma relação comercial, para isso determinada empresa oferece um serviço eficaz em longo prazo, visando um retorno que garanta o faturamento esperado, além de fidelização do cliente (Motta, 2008).

A satisfação dos consumidores aumenta a fidelização e também contribui para atrair novos clientes. Essa fidelidade resulta num efeito mais rápido, porém, é preciso manter esse consumidor cada vez mais satisfeito e fiel, o que instiga na diferenciação do serviço. Por isso, a importância de trabalhar com o marketing sustentável no ambiente natural para que os turistas ou consumidores estejam mais que satisfeitos, envolvidos e conscientes na preservação do meio ambiente (Carvalho, 2011).

No cenário mundial é notório a apreensão para que aconteça a real mudança sustentável, os compradores precisam ser aliados aos programas na busca de empresas, uma postura estabelecida nos princípios da sustentabilidade (social, ambiental e econômico), compreendendo que as mesmas podem usar a responsabilidade social para gerar vantagens e 
lucros de modo positivo, no entanto, na hora de colocar em prática, agem negativamente (Lourenço et al, 2017).

As ferramentas apropriadas para efetividade do princípio da sustentabilidade são educação ambiental e conscientização social por meio da orientação ética de valores e desempenhos sociais que vão ao encontro com os princípios da sustentabilidade e igualdade social. A educação ambiental atua como também o ferramenta adequada na validação da preservação da natureza (Marra, Bistene, Rosa \& Marques, 2011).

O consumo sustentável apareceu na década de 1970 com as preocupações ambientais, porém, só tomou maior proporção ao fim dos anos $80 \mathrm{com}$ acontecimentos relacionados a acidentes industriais, mudança climática dentre outros. Com essa discussão surge também a "nova" era do marketing, onde a avaliação dos consumidores perpassa desempenho ou preço com o foco voltado na sustentabilidade utilizada pelos fabricantes. Nesse sentido, o marketing sustentável aparece como mais uma ferramenta estratégica numa nova perspectiva dos administradores "verdes", que se apropriam dessa corrente para trabalhar com produtos considerados sustentáveis Schenini et al. (2000 como citado em Silva, Minciotti \& Romeiro, 2011). No estudo, de Buosi, Lima e Leocádio (2014), identificou-se que o desenvolvimento sustentável fortalece as características da imagem influenciando positivamente na imagem global avaliada pelos turistas.

Atualmente vivencia-se uma maior preocupação com o meio ambiente. Muitos fatores sociais influenciam nessa sensibilização ambiental, como as dificuldades ambientais sofridas pela população. A partir disso, surge o movimento contrário a globalização, coincidindo com a teoria da sustentabilidade, contribuindo com uma educação ambiental nas escolas, com isso, uma geração com maior responsabilidade ambiental (Muntean \& Stremtan, 2008).

Compromete-se assim, a viabilidade de trilhar novas possibilidades para o desenvolvimento humano e social pela análise do entendimento atuante na ciência e na economia do mercado, argumentadora a respeito aos consumos humanos e ambientais incluídos no padrão de consumo e na maneira de viver nas sociedades contemporâneas (Brandemburg; Bezerra \& Giordani, 2016).

O marketing sustentável, marketing societal e marketing verde se diferenciam do marketing tradicional de forma que estes vão ao encontro com os turistas que buscam qualidade de vida, que estão preocupados no reflexo de suas ações relacionados ao impacto que podem causar no meio ambiente e saúde. Estão buscando cada vez mais informação sobre consumo consciente, assim como, destinos que lhes ofereçam as características compatíveis com seus valores sustentáveis (Silva, Minciotti \& Romeiro, 2011). 
O conceito de "marketing verde" está atrelado com comportamento do turista consciente, políticas públicas e a sociedade. A sociedade moderna projeta consumidores cada vez mais exigentes, isso também em relação aos serviços turísticos que exigem não só a satisfação em necessidades básicas, mas também exige um elevado grau de qualidade de vida. O que permeia uma nova abordagem de marketing, uma relação mais intimista entre empresaconsumidor, se tornando elemento parceiro importante nessa nova discussão sustentável (Muntean \& Stremtan, 2008).

Marketing ambiental é um conjunto de transformações sustentáveis num aspecto ecológico, por meio de uma nova cadeia de serviços juntamente com a integração entre administração de distribuição, comunicação e publicidade, assim é possível prezar pela satisfação dos consumidores, bem como a exigência dos objetivos que abarcam as prioridades das organizações e da sociedade (Muntean \& Stremtan, 2008),

O turismo em áreas naturais preservadas é opção de destino de muitas pessoas, o qual necessita inserir um bom plano de manejo, boa infraestrutura, bem como a preocupação com a sua preservação (Meneguel \& Etchebehere, 2011). O marketing sustentável de um destino turístico está vinculado essencialmente na compreensão de como acontece à tomada de decisões do seu público alvo em adquirir ou aproveitar os produtos turísticos. O desenvolvimento de atividades turísticas pode melhorar a perspectiva na promoção e divulgação do turismo sustentável (Cobuci, Kastenholz \& Breda, 2011).

Embora o turismo de massa seja predominante, apareceram novos segmentos relacionados à cultura, ambiente, educação e saúde (Bejinaru \& Cozorici, 2016). Aumenta o interesse pelo o turismo de natureza e/ou de aventura em decorrência da atual preocupação com as questões ambientais que tem tomado grande importância entre as atividades humanas. Este crescente interesse surge com a inserção do meio ambiente natural e como objeto de pesquisa em varias áreas do conhecimento. Dentre essas áreas, o marketing aparece como resultado à medida que a sociedade que está mais envolvida em relação à sustentabilidade em áreas naturais, sendo necessário assumir um compromisso a esse novo comportamento (Dias, 2008).

A potencialidade do turismo sustentável é enorme, no entanto precisa valer-se de um novo conceito de marketing que utilize todas as características sustentáveis para estimular o crescimento dos destinos que possui tais propriedades ecológicas, para isso é essencial ter o domínio claro do marketing ambiental como ferramenta eficaz de sustentabilidade (Dias, 2008). 
A discussão a respeito do planejamento sustentável no ecoturismo vinculada a cadeia de serviços que fomentam a atividade turística como: áreas para camping, aparelhos de comunicação (placas, folders, etc.), serviços de alimentação dentre outros. Assim, estimar-se a qualidade destes e sua inclusão em espaços naturais, prezando sempre pelo o mínimo de impacto dessas áreas (Santos, Rezende, Borges \& Borém, 2011).

De acordo com o plano de marketing experiências do Brasil 2015-2018 do Ministério do Turismo (2014), a sustentabilidade está aliada ao conceito de turismo responsável sendo um assunto de grande relevância que incorpora aspectos ambiental, econômico, sociocultural e político institucional e está inteiramente relacionada com a valorização ambiental da atividade turística. Sendo imprescindível a sua integração nas ações previstas na implantação da politica Nacional do Turismo.

As ações do Plano de Marketing no Brasil estão voltadas na relação harmônica entre consumidores e cultura, assim como as organizações privadas e públicas. O turismo deve instituir o desenvolvimento sustentável buscando iniciativas relacionadas à acessibilidade e inclusão social como fomento da atividade turística nos destinos brasileiros (Ministério do Turismo, 2014).

Para a garantia da sustentabilidade em longo prazo é preciso alcançar o equilíbrio em vários aspectos, dentre eles: o ambiental, que significa a eficácia da gestão dos recursos naturais, conservação da biodiversidade; econômica, relacionada para geração de riquezas para sociedade; social, pautada na equidade das oportunidades na sociedade, no respeito dos direitos humanos, etc. Atingir esse nível de equilíbrio sustentável em todas essas dimensões no turismo é possível, desde que estas estejam integradas e não vistas como forças opostas (Leroux, 2010).

O equilíbrio é fundamental no uso racional dos recursos naturais, buscando assim a manutenção em longo prazo a praticabilidade da atividade turística com o objetivo de alcançar uma relação produtiva e harmoniosa entre o visitante, a comunidade local e o destino turístico visitado (Burgos \& Mertens, 2015).

O Brasil apresenta um amplo conjunto de aéreas naturais com grande potencial turístico, muitas são protegidas em Unidades de Conservação (UC). Neste contexto, o turismo que se apropria desses ambientes como produtos necessariamente deve ter uma preocupação em manter essas áreas preservadas. Dentre as UCs que apresentam condições adeptas para atividades turísticas são os Parques Nacionais. Conforme o art. $7^{\circ}$, da Lei n. 9.985 (2000), que institui o Sistema Nacional de Unidades de Conservação - SNUC (Santos et al., 2011). 


\subsection{Turismo sustentável em áreas naturais protegidas}

A sustentabilidade, é um conceito fundamental no mundo atual. Economicamente o turismo é uma das atividades mais importantes dos países e, como tal, a sua contribuição na aplicabilidade da sustentabilidade pode ser essencial. Assim, é necessária uma mudança em alguns comportamentos na cadeia produtiva do turismo que inclui não só turistas, mas também de todos os atores envolvidos nesta atividade. Para atingir o objetivo da sustentabilidade é preciso mudar atitudes sendo que o marketing sustentável se configura como uma ferramenta eficaz em benefício da sustentabilidade. (Araújo \& Sá, 2017).

Considerando que o desenvolvimento sustentável do turismo recompensa as necessidades dos turistas atuais e das regiões receptoras enquanto cuida e perpetua possibilidades futuras, precisa-se evidenciar a necessidade de um manejo de todos os recursos, de forma que necessidades econômicas, sociais e estéticas possam ser sanadas enquanto a integridade cultural, processos biológicos fundamentais, diversidade biológica e sistemas de suporte da vida são conservados (Organização Mundial de Turismo e o Programa das Nações Unidas para o Meio Ambiente - PNUMA).

O conjunto de princípios operacionais dos sistemas, como é compreendido a sustentabilidade, permite definir um estilo de desenvolvimento sustentável como uma alternativa social que insere objetivos diversificados, conforme escalas de valores estabelecidos e circunstâncias variáveis que irão modificando no tempo e se retroalimentam constantemente. De qualquer forma, estas definições, estão mais atados ao pensamento de mudança do que ao de permanência, habitualmente ligada a manter um sistema de forma perene para proteger um determinado estado (Jiménez Herrero, 2006).

O turismo sustentável compreende em sua totalidade os serviços básicos na satisfação do turista, junto a isso preza pela preservação dos destinos e das regiões a qual está inserido, além de fomentar futuras oportunidades. Ainda fortalece a gestão de recursos existentes, tanto da ótica econômica, social e estética, quanto à conservação da diversidade biológica e a integridade cultural (OMT, 1998).

Neste cenário, alguns estudos contribuem para a significância da sustentabilidade do lugar como condição a ser destacada no planejamento de marketing, a sustentabilidade do lugar é o triunfo do destino turístico no longo prazo. Enquanto prática econômica, quando não gerida de forma eficiente, a atividade turística pode resultar em impactos negativos para o destino turístico (Buhalis, 2000).

De acordo com a World Tourism Organization - WTO (2004), alguns documentos resultantes de importantes reuniões internacionais contribuíram para a elaboração dos 
princípios do Turismo Sustentável, entre eles a Declaração de Manila no Turismo Mundial em 1980, o Documento de Acapulco sobre o Direito às Férias - México, 1982, o Código do Turismo de Sofia sobre os direitos e deveres do Turismo - Bulgária, 1989, a Declaração do Turismo de Hague, Holanda, 1989, a Declaração de Prevenção do Turismo Sexual Organizado do Cairo, Egito, 1995, a Agenda 21 para o Turismo e a Indústria de Viagens, 1996, o Código Global de Ética para o Turismo, 1999, a Declaração de Hainan sobre o Turismo Sustentável nas Ilhas das Regiões Asia-Pacífico - China, 2002, Declaração de Djerba sobre o Turismo e as Mudanças Climáticas - Tunísia, 2003.

O turismo é fundamental no desenvolvimento e competitividade de determinada comunidade que possui potencial turístico natural e cultural. Os autores dizem ainda, que a atividade turística é de ampla importância no mundo, sendo que no México o turismo atua beneficamente tanto na geração de empregos quanto no desenvolvimento regional, assim promove a cultura e seus recursos naturais existentes (Sánchez, Félix, Andrade \& Chávez, 2011).

O desenvolvimento do turismo sustentável está acompanhado de ações continuas, monitoradas constantemente em relação aos impactos, apresentando soluções de prevenção sempre que necessárias. Além de determinadas atuações, o desenvolvimento sustentável do turismo depende do envolvimento de todos os interessados, como por exemplo, comunidade, lideranças politicas para garantir vasta participação e que haja um consenso nas decisões. Considerando, também que deve cultivar turistas altamente satisfeitos para assegurar uma experiência que alimente sua consciência a respeito da sustentabilidade e consequentemente permitindo comportamentos sustentáveis (Niedziólka, 2014).

A definição de turismo sustentável está atrelada, a integração aos seguintes aspectos a integridade ambiental, desenvolvimento econômico e sociocultural. Essa tríplice da sustentabilidade tem como princípio garantir a conservação dos recursos naturais e culturais (Leroux, 2010; Falcão \& Gómes, 2012; Niedziólka, 2014).

Por meio do turismo sustentável é possível que as características culturais possam fortalecer a valorização da identidade local, bem como, é potencialmente mais um incremento na promoção do destino. Da mesma forma acontece com o desenvolvimento social local ao mesmo tempo em que se promove o turismo numa região e necessita que esta esteja preparada para receber o turista com serviços básicos como: educação, saúde, segurança, transporte, dentre outros, são benefícios ao alcance do morador. Outro fator importante é não visualizar o crescimento econômico como um único benefício do turismo, mas nas estratégias pública 
deve ser visto como multidimensional e todos os aspectos da sustentabilidade estejam contemplados (Falcão \& Gómes, 2012).

As mais variadas tentativas de implantação dos princípios da sustentabilidade devem envolver todos os atores que desenvolvem o turismo, como comunidade, empresas de turismo, poder público, dentre outros. O turismo sustentável trabalha com questões importantes, onde as empresas de turismo competitivas precisam ser socialmente responsáveis com a participação da comunidade com mais oportunidades de emprego e responsabilidade ambiental (Niedziólka, 2014).

O Brasil apresenta um amplo e diversificado cenário de ambientes naturais capaz de potencializar o turismo, inúmeras dessas áreas fazem parte de Unidades de Conservação. A partir disso, vários fatores registram aumento significativo da visitação, sendo um indicador de motivação as atividades vinculadas à natureza. Nesse sentido, o turismo se apropria da natureza e ajuda na sua conservação, com isso movimenta a economia local e incentiva a manutenção destas áreas. No entanto, implica em unir turismo responsável ligado a riqueza sociocultural, aos conhecimentos locais e a preservação da sua biodiversidade (Minc, 2008).

Se tratando da visitação em Unidades de Conservação é necessário atender a ambiências especificas no desenvolvimento das atividades turísticas e de lazer. Ou seja, ambiências são formadas dos ambientes naturais do local que é o atrativo principal, e de elementos inseridos pelo ser humano que dão suporte aos visitantes, dos turistas, e questões relacionados à gestão, visando sempre à preservação e manutenção do patrimônio natural e cultural (Sobral-Oliveira, Cunha, Gomes \& Santos 2009).

Estimular a visitação nos parques nacionais implica no incentivo e a consolidação de ações responsáveis em aéreas protegidas, visando um público do próprio país. A disseminação do turismo nos espaços dos parques nacionais engloba a participação democrática de todos os atores envolvidos com atividade turística. Isso significa que o turismo deve estar alinhado a boas práticas, aumento de receitas, diversificação de atrações, conhecimento, dentre outros benefícios. Tudo isso, faz parte do desenvolvimento sustentável que preza pela conservação do meio ambiente e o elo sadio com a presença humana, que precisa de planejamento apropriado (Santos; Carvalho, 2015).

Atualmente no turismo tem-se adotado os avanços tecnológicos para incrementar o seu desenvolvimento utilizando arranjos inovadores. A partir disso, determinados locais alcançam o elo entre crescimento econômico regional com conservação ambiental (Santos; Carvalho, 2015). 
Dentre desses arranjos inovadores o marketing sustentável surge como uma ferramenta de fomento do turismo em parques nacionais ao mesmo tempo em que atua como facilitador para as organizações. Essas empresas que adotam ações ecologicamente corretas sem traçar a estratégia certa, tendem a não conseguirem o resultado esperado. No entanto a implantação bem-sucedida de ações ambientais necessita de atitudes proativas, pois as empresas que tem estratégia proativa conseguiram acompanhar o mercado (Yang, Zhao, Lou \& Wei, 2013).

Os objetivos do turismo sustentável estão vinculados a uma estratégia que visa um crescimento do número de visitantes comprometidos com os princípios sustentáveis. No entanto para alcançar esse objetivo é preciso seguir aspectos específico tais como: a organização de todos os atores interessados em desenvolver o turismo de determinada comunidade; detectar os produtos turísticos; prezar por unir o interesse da localidade, do meio ambiente no desenvolvimento das atividades e do produto e marketing sustentável; verificação desse marketing em relação à visão de possíveis compradores; atribuir estratégias voltadas para atividades de visão, missão e plano de marketing em longo prazo; criar marca comum da região (Niedziólka, 2014).

O ecoturismo é o segmento que representa fundamentalmente essa junção entre os interesses industriais do turismo em colaboração com a natureza. Nesse sentido, o enfoque do marketing implica a realização de três obrigações, o bem estar do visitante no ambiente provisoriamente modificado, a importância da preservação do meio natural, assim como a necessidade da oferta de informações sobre o turismo. Essas três situações estão vinculados de tal forma que o produto turístico que precisa atender estes requisitos e deve estar interligados, pois isso envolve o que a natureza recebe, sendo importante analisar previamente até onde compromete a sua preservação (Meler \& Ham, 2012).

Portanto, o ecoturismo é o segmento que possui características que vão de encontro com a conexão entre a utilização do meio natural e a concepção dos valores ambientais. Isso devido à mudança da relação entre a sociedade e natureza. Assim, para assegurar um equilíbrio entre o homem e o meio ambiente natural é necessário averiguar se os princípios básicos estão sendo seguidos, como a integração entre sustentabilidade, conservação e o envolvimento da comunidade que adota a atuação do ecoturismo (Campos, 2005). Fundamentalmente as características locais moldam e são moldadas por aspectos econômicos, socioculturais, políticos, ecológicos, além de técnicas que são exógenas e intrínsecas. Nesse contexto o ecoturismo tem um papel de grande importância para desempenhar resultados sustentáveis (Cater \& Cater, 2015). 


\section{OS PARQUES MAIS VISITADOS DO BRASIL}

Para verificar se os Parques, que estão dentro das Unidades de Conservação do Brasil estão conseguindo aumentar seu número de visitantes, e com isso, ampliar a visibilidade de seus destinos turísticos, escolheu-se os três parques mais visitados para fazer a avaliação. Esta avaliação se deu pelo número de visitas que cada Parque recebeu nos últimos anos. Os parques escolhidos foram: Parque Nacional da Tijuca, Parque Nacional do Iguaçu e Parque Nacional de Jericoacoara.

Atualmente, o instituto que registra o número de visitantes dos parques nacionais é o Instituto Chico Mendes de Conservação da Biodiversidade - ICMBio. Desde a sua criação em 2007, no ano de 2017 foi o maior aumento de visitantes registrados. Foram 10,7 milhões de pessoas que buscaram vivenciar momentos em meio à natureza nas unidades de conservação geridas pelo ICMBio, conforme dados demonstrados na Figura 1.

Figura 1 - Ucs mais visitadas segundo o ICMBio.

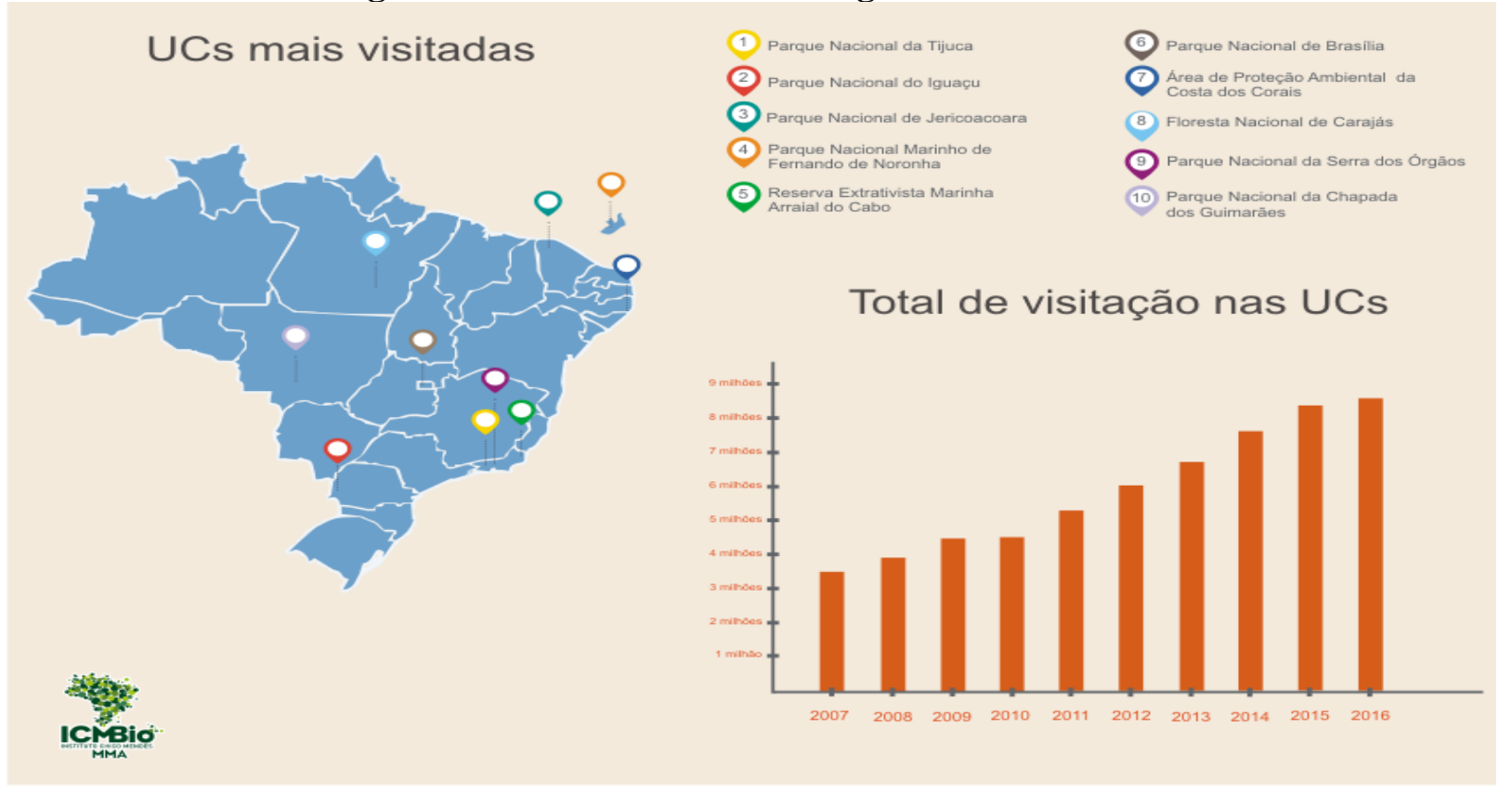

Fonte: ICMBio (2018).

De acordo com a entrevista com o presidente do órgão, Ricardo Soavinski, divulgada pelo próprio ICMBio (2018), o incremento na visitação dos parques reflete a melhoria na qualidade dos serviços ofertados, consequentemente reflete em um maior interesse das pessoas pela natureza e pela recreação em espaços naturais. Esse dado já demonstra que os parques vem conseguindo, por meio de suas ações, aumentar o interesse do público a visitar essas localidades, bem como, visitar esses locais de conservação. 
Tabela 1 - Número de visitantes dos três principais Parques Nacionais do Brasil

\begin{tabular}{|l|c|c|c|c|c|c|c|c|c|}
\hline Parque/Ano & $\mathbf{2 0 1 7}$ & $\mathbf{\%}$ & $\mathbf{2 0 1 6}$ & $\mathbf{\%}$ & $\mathbf{2 0 1 5}$ & $\mathbf{\%}$ & $\mathbf{2 0 1 4}$ & $\mathbf{\%}$ & $\mathbf{2 0 1 3}$ \\
\hline $\begin{array}{l}\text { Parque } \\
\text { Nacional da } \\
\text { Tijuca }\end{array}$ & $\begin{array}{c}3,3 \\
\text { milhões }\end{array}$ & $+23 \%$ & $\begin{array}{c}2,7 \\
\text { milhões }\end{array}$ & $-6,9 \%$ & $\begin{array}{c}2,9 \\
\text { milhões }\end{array}$ & $-6,9 \%$ & $\begin{array}{c}3,1 \\
\text { milhões }\end{array}$ & $+6,45 \%$ & $\begin{array}{c}2,9 \\
\text { milhões }\end{array}$ \\
\hline $\begin{array}{l}\text { Parque } \\
\text { Nacional do } \\
\text { Iguaçu }\end{array}$ & $\begin{array}{c}1,8 \\
\text { milhões }\end{array}$ & $+12,5 \%$ & $\begin{array}{c}1,6 \\
\text { milhões }\end{array}$ & $0 \%$ & $\begin{array}{c}1,6 \\
\text { milhões }\end{array}$ & $+6,5 \%$ & $\begin{array}{c}1,5 \\
\text { milhões }\end{array}$ & $0 \%$ & $\begin{array}{c}1,5 \\
\text { milhões }\end{array}$ \\
\hline $\begin{array}{l}\text { Parque } \\
\text { Nacional do } \\
\text { Jericoacoara }\end{array}$ & 800 mil & $+3 \%$ & 780 mil & $0 \%$ & 780 mil & $+48,7 \%$ & 400 mil & - & $\begin{array}{c}\text { Dados } \\
\text { não } \\
\text { encontrados }\end{array}$ \\
\hline
\end{tabular}

Fonte: Elaborado pelos autores com base nos dados do ICMBio, Parque Nacional da Tijuca, Cataratas do Iguaçu S.A., Ministério do Turismo (2018).

Segundo dados divulgados pelo ICMBio, dentre os parques mais visitados em 2017 encontra-se em primeiro lugar o Parque Nacional da Tijuca, localizado no Rio de Janeiro, que recebeu 3,3 milhões de pessoas, e, 2016, foram 2,7 milhões. O Parque do Iguaçu, no Paraná, parque onde estão localizadas as Cataratas do Iguaçu, uma das 7 maravilhas do mundo, é a segunda unidade mais visitada, com 1,8 milhões de turistas, e em 2016 foram 1,6 milhões. O terceiro parque mais visitado é Parque Nacional do Jericoacoara, no Ceará, com 800 mil visitantes durante o ano de 2017.

Conforme percebido na Tabela 1, ao considerar os últimos 5 anos, notou-se um grande aumento no número de visitante dos três parques. Nota-se que, em 2014 o Parque Nacional da Tijuca apresentou um número de visitantes maior do que o ano seguinte, 2015, acredita-se que esse fato tenha acontecido em virtude da Copa do Mundo, que aconteceu no Brasil no ano de 2014 e com isso, acabou trazendo um número ainda maior de visitantes ao país. Tirando este dado, todos os outros foram aumentos consideráveis, principalmente do Parque Nacional do Jericoacoara, que em 2014 recebeu apenas 400 mil visitantes e dobrou este número em apenas 3 anos.

De acordo com informações divulgadas no site do Ministério do Turismo (2018), atualmente o Brasil é considerado o país número $1 \mathrm{em}$ atrativos naturais, de acordo com o Fórum Econômico Mundial, e os parques nacionais abrigam toda a beleza e diversidade que compõem as paisagens que encantam turistas brasileiros e estrangeiros. Acredita-se que em virtude disto o número crescente de visitantes nas Unidades de Conservação e Parques Nacionais do país.

Buhalis (2000), aponta para a significância da sustentabilidade do destino como sendo uma condição a ser destacada no planejamento de marketing, e por meio disso, a sustentabilidade do destino se torna o triunfo do destino turístico no longo prazo, como podese perceber através dos número divulgados, com o crescimento constante de visitantes não 
somente nos três parques que mais são visitados no país, mas também nos outros, todos tiveram aumentos consideráveis de visitas nos últimos anos, isso demonstra que no longo prazo os planejamentos de marketing dessas localidades está sendo eficaz.

Como consequência deste aumento, o número de turistas nestes destinos se torna maior, bem como sua visibilidade, tanto no Brasil, quando mundo afora. Para Sánchez et al. (2011), o turismo é peça fundamental no desenvolvimento e competitividade de determinada comunidade que possui potencial turístico natural e cultural.

De acordo com Niedziólka (2014) o desenvolvimento do turismo sustentável vem acompanhado sempre de ações continuas, monitoradas constantemente em relação aos impactos, apresentando soluções de prevenção sempre que necessárias. Principalmente quando se trata de locais ambientais que não podem sofrer com o impacto dos turistas, em virtude disso, a Vila de Jericoacoara visa diminuir o número de visitantes no Parque, principalmente agora que a cidade vizinha ganhou um novo aeroporto, pois a Vila já recebe mais de 600 mil visitantes por ano, e com isso visam diminuir os impactos causados. Desde setembro de 2017 , já é cobrada taxa de $\mathrm{R} \$ 5$ por dia para cada turista que entra na vila de Jericoacoara, sendo que $40 \%$ desse valor obrigatoriamente têm que ser usados na preservação ambiental (Portal O Dia, 2018).

As Unidades de Conservação constituem um importante plano de proteção da natureza, objetivando essencialmente assegurar a sobrevivência da biodiversidade e da geodiversidade para as futuras gerações. Isso, devido à preocupação com o atual processo de desenvolvimento global, por causa das mudanças aceleradas pela ação humana no ambiente natural (Baptista \& Moreira, 2017).

Conforme informações divulgadas pelo Minc (2008), o Brasil possui um diversificado cenário de ambientes naturais, e estes são capazes de potencializar o turismo, principalmente as áreas que fazem parte das Unidades de Conservação. Analisando os dados na tabela, podese perceber que as UCs realmente têm grande potencial para atrair turistas não somente para as cidades, mas também para dentro dos Parques. A valorização turística em áreas protegidas é de responsabilidade da gestão das mesmas, entre as áreas protegidas que podem ser desenvolvidas atividades turísticas, estão os parques nacionais que possuem uma estratégia de gestão baseada na sustentabilidade no uso dos recursos naturais (Jurdana \& Zmijanovic, 2014). 


\section{CONSIDERAÇÕES FINAIS}

Ao longo do ensaio teórico apresentado pode-se indicar a correlação dos temas abordados: o marketing sustentável e o turismo sustentável e apontar a importância dessa discussão para o cenário atual no Brasil. Entende-se neste estudo que, os princípios da sustentabilidade prezam pela conservação dos fatores culturais, sociais e ambientais, por isso, é o melhor caminho a ser seguido na conservação das áreas naturais onde o turismo é fonte de crescimento econômico para a comunidade local. O marketing sustentável surge como um potencial de integração de ações voltadas para a disseminação dos valores ambientais, bem como é utilizado como uma estratégia de alcançar o turista que busca está inserido na atividade turística praticada na natureza e aumentar o numero de adeptos.

No entanto, o Ministério do Turismo (2014) desenvolveu um Plano Estratégico de Marketing - Experiências do Brasil no período 2014-2018. Este plano estabelece ações a ser desenvolvidas em quatro dimensões: competitividade e inovação da oferta turística; fortalecimento da cooperação público-privada; gestão da demanda em mercados prioritários; efetividade da promoção e comunicação. Porém, dentre esses programas estratégicos a sustentabilidade aparece em ultimo lugar nas prioridades do item competitividade e inovação da oferta turística como "fomento à sustentabilidade no turismo brasileiro". Isso mostra por que ainda se estar engatinhando no diz respeito ao uso sustentável dos recursos naturais em relação ao resto mundo.

Também foi possível perceber que as ações de marketing desenvolvidas pelos Parques Nacionais e pelas Unidades de Conservação do Brasil estão trazendo grandes resultados para esses locais, visto que, os números de visitantes só aumentaram nos últimos 5 anos. Esse aumento de visitantes costuma trazer benefícios não só para os Parques e UCs, mas também para os destinos, redes hoteleiras, comercio, etc.

Porém, nota-se que quando se trata de sustentabilidade, esta precisa evoluir por meio de um planejamento efetivo de marketing sustentável com estratégias claras e objetivas sobre amplitude de seu desenvolvimento.

Dentre as limitações encontradas para o presente trabalho, encontra-se as dificuldades de encontrar alguns dados referentes aos parques estudados, principalmente para que se tivesse maior certeza sobre as ações de marketing sustentável que estes estão (ou não) fazendo.

Para futuras pesquisas sugere-se realizar uma pesquisa qualitativa com os gestores desses parques, para que por meio dela, seja possível identificar quais ações estão fazendo para aumentar o número de visitantes e ampliar a visibilidade dos Parques, principalmente 
considerando ações fora do Brasil, e por meio dos números, verificar se estas estão sendo eficazes ou não.

\section{REFERÊNCIAS}

Araújo, C., \& Sá, E. S. (2017). A importância do marketing social no turismo: revisão da literatura. Revista Turismo \& Desenvolvimento, 27(28), 713-731.

Baptista, L., \& Moreira, J. C. (2017). Ecoturismo de base comunitária no Parque Nacional dos Campos Gerais-PR: a ótica das comunidades de entorno. Revista de Turismo y Patrimonio Cultural, 15(1), 195-210. Recuperado de http://www.pasosonline.org/en/articles/1022-elecoturismo-basado-en-la-comunidad-en-el-parque-nacional-campos-gerais-pr-la-perspectivade-las-comunidades-locales

Bejinaru, R., \& Cozorici, A. N. (2016). Challenges for Romanian Ecotourism Destinations. Revista de Turism - Studii si Cercetari in Turism, 22, 61-68

Brandemburg, A., Bezerra, I., \& Giordani, R. C. F. (2016). Soberania alimentar, desenvolvimento territorial e sustentabilidade: olhares e contextos. Revista Brasileira de Desenvolvimento Territorial Sustentável, 2(1), 2-13

Buhalis, D. (2000). "Marketing the competitive destination of the future". Tourism management, 21(1), 97-116.

Buosi, M. C. A., Lima, S. H. O., \& Leocádio, A. L. (2014) A relação entre desenvolvimento sustentável e imagem de lugar de um destino turístico: proposição de um modelo estrutural. Revista Brasileira de Pesquisa em Turismo. São Paulo, 8(2), 261-285

Burgos, A., \& Mertens, F. (2015). Os desafios do turismo no contexto da sustentabilidade: as contribuicoes do turismo de base comunitária. PASOS. Revista de Turismo y Patrimonio Cultural, 13(1),57-71

Campos, A. M. (2005). “O ecoturismo como alternativa de desenvolvimento sustentável”. Caderno Virtual de Turismo, 5(1).

Carvalho, M. J. P. J. (2011). "A importância do marketing relacional para a sustentabilidade dos empreendimentos de alojamento no turismo natureza". Tourism \& Management Studies, (1), 447-456.

Cataratas do Iguaçu S.A. Mais de 1 milhão e 700 mil pessoas visitaram o Parque Nacional do Iguaçu em 2017. Recuperado em 17, agosto, 2018 de http://www.cataratasdoiguacu.com.br/imprensa/noticias/2018/01/mais-de-1-milhao-e-700mil-pessoas-visitaram-o-parque-nacional-do-iguacu-em-2017.

Cater, C., \& Cater, E. (2015). Ecotourism. International Encyclopedia of the Social \& Behavioral Sciences, 2nd edition,7

Cobuci, L., Kastenholz, E., \& Breda, Z. (2011). "O turismo residencial em meio rural numa perspectiva do Marketing Sustentável dos destinos”. Tourism \& Management Studies, 1. 
Dias, R. (2008). "Marketing ecológico y turismo". Estudios y perspectivas en turismo, 17(2), 76-91.

Falcão, M. C., \& Gómez, C. R. P. (2012). “Análise da Sustentabilidade de Destinos Turísticos: uma proposta teórica de adequação do modelo de ciclo de vida de áreas turísticas às dimensões da sustentabilidade”. Turismo, Visão e Ação, 14(3), 304-321.

ICMBio/Ministério do Turismo. Visitação nos parques nacionais cresce 20\% em 2017. Recuperado em 10, novembro, $2017 \mathrm{de}$ http://www.icmbio.gov.br/portal/ultimas-noticias/20geral/9484-visitacao-nos-parques-cresce-20-em-2017.

Jiménez Herrero, L. M. (2006). "Los procesos de sostenibilidad en España”. Ambienta, Madrid, 8-19.

Jurdana, D. S., \& Zmijanovic, L. (2014). The effect of tourism seasonality on protected areas. Tourism and Hospitality Industry, Congress proceedings.

Leroux, E. (2010). “Tourisme durable et écotourisme: des méthodes de calcul liées au marketing”. Gestion 2000, 27(1).

Lourenço, M. C. M., Novôa, H. A. S., Silva, G. C., \& Siqueira, J. C. C. (2017). Marketing sustentável e a Educação ambiental. Revista PluriTAS, 1(1).

Marra, N. C., Bistene, R. L., Rosa, R. H. S., \& Marques, M. R. (2011). “ocupação sustentável do entorno do Parque do Sumidouro". Revista Geográfica de América Central, 2, 1-17.

Meler, M., \& Ham, M. (2012). “Green marketing for green tourism”. In Faculty of Tourism and Hospitality Management in Opatija. Biennial International Congress. Tourism \& Hospitality Industry, 130. University of Rijeka, Faculty of Tourism \& Hospitality Management.

Meneguel, C. A., \& Etchebehere, M. L. D. C. (2011). "Parques nacionais no Brasil e a prática do turismo sustentável". Revista Hospitalidade, 8(1), 78-94.

Minc, C. (2008). "Ministro do Meio Ambiente". Programa de Turismo nos Parques. Ministério do Meio Ambiente. Dados de Visitação 2007 - 2016. Recuperado em 18, agosto, 2017 de http://www.icmbio.gov.br/portal/images/stories/comunicacao/noticias/2017/dados_de_visitac ao_2012_2016.pdf.

Ministério Do Turismo. (2014). "Plano estratégico de marketing turístico do Brasil experiências do Brasil". Recuperado de http://www.terrabrasilis.org.br/ecotecadigital/index.php/estantes/acoes-com-o-entorno/3596plano-estrategico-de-marketing-turistico-do-brasil-experiencias-do-brasil

Ministério do Turismo. (2018). Recuperado de http://www.turismo.gov.br/2018.html

Motta, S. L. S. (2008). "Competitividade baseada no marketing ecológico". Revista de Ciências da Administração, 10(22), 128-145. 
Muntean, A., \& Stremtan, F. (2008). "Green Marketing: a New Challenge for Romanian Organizations". Tourism and hospitality management, 14(2), 343-348.

Niedziółka, I. (2014). "Sustainable tourism development”. Regional formation and development studies, 8(3), 157-166.

Organização Mundial de Turismo - OMT. (2003). "Guia de Desenvolvimento do Turismo Sustentável, Tradução Sandra Netz”. Porto Alegre: Ed. Brokamn.

Parque Nacional da Tijuca. Visitação no Parque Nacional da Tijuca. Recuperado em 17, agosto, 2018 de

https://public.tableau.com/profile/equipe.pnt\#!/vizhome/VisitaonoParqueNacionaldaTijuca/Vi sitaonoPNT.

Portal O Dia. Após ganhar aeroporto, Jericoacoara quer limitar o número de visitantes. Recuperado em 17, agosto, 2018 de https://www.portalodia.com/noticias/economia/aposganhar-aeroporto,-jericoacoara-quer-limitar-o-numero-de-visitantes-315893.html.

Sánchez, R. E., Félix, E. C., Andrade, E., \& Chávez, R. M. (2011). "Breve Estudio Sobre La Oferta De Las Empresas De Turismo De Naturaleza En El Municipio De Cabo Corrientes", Jalisco, México. Turismo y Desarrollo Local, (10).

Santos, A. A., Rezende, J. L. P., Borges, L. A. C., \& Borém, R. A. T. (2011). “Cadeia de serviços turísticos: possibilidade de inclusão social nos parques nacionais brasileiros ”. Revista Brasileira de Ecoturismo, 4(2).

Santos, J. S. C., \& Carvalho, M. C. M. H. (2015). "Turismo em parques nacionais brasileiros: conhecer para conserver". Anais do II Encontro Fluminense de Uso Público em Unidades de Conservação. Turismo, recreação e educação: caminhos que se cruzam nos parques. Niterói, RJ / Brasil. Recuperado em 01 a 04, julho, 2015 de www.rjusopublico.uff.br.

Silva, E. C., Minciotti, S. A., \& Romeiro, M. C. (2011). "Marketing societal: uma contribuição para o crescimento sustentável das organizações". Revista de Administração da UFSM, 4(1), 19-38.

Sobral-Oliveira, I. S., Cunha, C., Gomes, L. J., \& Santos, J. (2009). "Planejamento de trilhas para o uso público no Parque Nacional Serra de Itabaiana", SE. Turismo, Visão e Ação, 11(2), 242-262.

Toaldo, A. M. M., \& Luce, F. B. (2006). "Estratégia de marketing: contribuições para a teoria em marketing”. Revista de Administração de Empresas, 46(4), 1-11.

World Tourism Organization - WTO. (2004). Recuperado em 11, setembro, 2018, de http://www.world- tourism.org/frameset/frame_sustainable.html

Yang, D., Zhao, P., Lou, R., \& Wei, H. (2013). "Environmental marketing strategy effects on market-based assets”. Total Quality Management \& Business Excellence, 24(5-6), 707-718. 
KRAUS, C. B., RICCI, R. M. G., SANTOS, G., \& SANTOS, P. (2018). Pesquisa empírica: turismo em áreas naturais e o uso do marketing sustentável. Revista de Turismo Contemporâneo, 6(2), 251-269. 